\title{
Relevance, Conduction and Canada's Rape-Shield Decision ${ }^{1}$
}

\author{
DEREK ALLEN University of Toronto
}

Key Words: Canadian Supreme Court decision; Canada's 1982 rape-shield legislation; informallogic class; relevance; conductive argument; "ar-gument from "unchasteness"; George Bowles's theory of propositional relevance; Trudy Govier's account of a conductive argument.

Abstract: I examine a Canadian Supreme Court decision concerning the constitutionality of Canada's 1982 rape-shield legislation, and suggest how material from the decision might profitably be used in an informal-logic class in connection with the topics of relevance and conductive argument. I also consider theoretical matters related to the decision: first I develop two analyses of what I call an argument from 'unchasteness' and connect them to George Bowles's theory of propositional relevance; then I present Tnudy Govier with a problem in response to which she might revise her account of a conductive argument in a way I describe.

The Parliament of Canada recently enacted legislation to amend sections of the Canadian Criminal Code pertaining to the offence of sexual assault. The legislation came in the wake of a Supreme Court decision that struck down one of the country's two rape-shield laws. In Part 1 of this paper I examine that decision, in the belief that it promises to be of pedagogical and theoretical interest within the informal-logic community. In Part 2 I offer suggestions as to how material from the decision might profitably be used in an informal-logic class in connection with the topics of relevance and conductive argument. In Part 3 I turn to theoretical matters related to the decision, having to do with those same topics.

\section{The Decision}

\section{Background:}

The rape-shield decision was in part a constitutional decision involving the Cana- dian Charter of Rights and Freedoms. The Supreme Court was called upon to decide whether two sections of the Canadian Criminal Code, commonly known as the rape-shield laws, infringed certain Charter rights. The first section (s. 276) provided that in a sexual-assault trial evidence concerning the sexual activity of the complainant with any person other than the accused was not admissible in defence of the accused except under one or more of three narrowly defined conditions. The second section (s. 277) provided that in a sexual-assault trial evidence concerning the sexual reputation of the complainant was not admissible for the purpose of challenging or supporting the complainant's credibility.

The rape-shield laws were enacted in 1982. Their main purpose was to deal with a problem in the common law. The problem was that the common law allowed sexual-history evidence and sexual-reputation evidence to be presented in a sexual-assault trial even if it was of little relevance and would mislead the jury, and allowed the jury to draw improper inferences from such evidence. For example, if Smith had been accused of raping Jones, and there were evidence that Jones had had consensual non-marital sex with Brown, the common law would have permitted a jury to infer from this evidence that Jones was more likely to have consented to have sex with Smith on the occasion in question, and less credible as a witness, than she would have been had she been 'chaste'. The main purpose of the rape-shield laws was to abolish the old common-law rules that allowed such inferences to be drawn. There 
were also three subsidiary purposes. One was to prevent judges and juries from being diverted by irrelevant and prejudicial evidence. A second was to encourage the reporting of sexual assaults. The third was to protect the privacy of the complainant.

The laws had the effect of limiting the defence strategies available to the accused in a sexual-assault trial. Consequently they had the potential to help determine whether the accused was convicted, imprisoned and thus deprived of liberty. But s. 7 of the Charter says that a person has the right not to be deprived of liberty except in accordance with the principles of fundamental justice. So the question arose whether the potential deprivation of liberty that followed from the rape-shield laws occurred in a manner that conformed to the principles of fundamental justice. A further and related question was whether the laws infringed the right of an accused person to a fair trial, a right proclaimed in s. 11(d) of the Charter. A negative answer to the first question, however, would not by itself mean that the laws were unconstitutional, nor would an affirmative answer to the second. For the Charter allows in its first section that the rights it enumerates are subject to reasonable limits-in particular, "to such reasonable limits prescribed by law as can be demonstrably justified in a free and democratic society." Thus if the Supreme Court decides that a law violates a Charter right, it must go on to ask whether the law can nevertheless be 'saved' under s. 1 of the Charter.

The Court delivered its decision on the constitutional validity of the rape-shield laws in August, 1991. All nine judges agreed that one of the laws-the sexualreputation law (s. 277)-was constitutional. But they disagreed about the other-the sexual-history law (s. 276): two of the judges held that the law was constitutional, seven that it was not.

Madam Justice Beverley McLachlin wrote the majority opinion. Madame Justice Clair L'Heureux-Dubé wrote an opinion partially dissenting. I shall now summarize parts of both opinions, beginning with McLachlin's.

\section{McLachlin:}

To be admissible in a trial, evidence must be relevant. This means that it must have probative value-it must count for or against some claim whose truth is at issue in the trial. But it is generally accepted throughout the common law world that Crown evidence against the accused in a criminal trial, even if it is relevant, may properly be excluded if, were it to be admitted, it would have a prejudicial effect exceeding its probative value - as it might in a jury trial if, for example, it would unduly arouse in the jury emotions of hostility or sympathy. When, however, prejudicial evidence is for the defence, the prejudicial effect it would have if admitted must $s u b$ stantially outweigh its probative value before a judge can exclude it. This is because a free and democratic society attaches great importance to the principle that an innocent person must not be convicted.

McLachlin makes these points by way of background (66 Canadian Criminal Cases (3d) 389g-391f). She then asks the following question: "can it be said a priori ... that any and all evidence excluded by s. 276 will necessarily be of such trifling weight in relation to the prejudicial effect of the evidence that it may fairly be excluded?" (392h-393a) Her answer is no, and she cites supporting examples. The most striking is an American case (State $v$. Jalo, Oregon Court of Appeal 1976) in which a father discovered that his son and daughter were having sexual relations. He stopped the relationship and subsequently his daughter accused him of the act. At his trial the father sought to present his discovery as evidence supporting his defence that the accusation was "a concoction motivated by animus" (393g). Under s. 276, McLachlin claims, the evidence would have been excluded-"[n]otwithstanding 
its clear relevance" (393g) and (as she presumably believes but does not say) notwithstanding that its probative value would have substantially outweighed such prejudicial effect as it might have had.

From this and other examples McLachlin concludes that s. 276 "overshoots the mark" (395f) and creates a real risk that an innocent person will be convicted. For this reason, she further concludes, the legislation infringes the Charter right to a fair trial.

But can it nevertheless be saved under s. 1 of the Charter? McLachlin argues that it cannot, partly because it "strikes the wrong balance between the rights of complainants and the rights of the accused" (403f).

\section{L'Heureux-Dubé:}

L'Heureux-Dubé begins her (partial) dissent by arguing that sexual assault is unlike any other crime. It goes largely unreported and has the lowest prosecution and conviction rates of all violent crimes. One reason why prosecution rates are low is that "very few cases that come to the atten. tion of the police are classified as founded" (338d). Those that are so classified are cases that the police believe likely to result in convictions. And in deciding what cases are likely to result in convictions, the police rely on beliefs about what a model rapist is like and what a model rape victim is like-beliefs that reveal the influence within the judicial system of stereotypes about women and myths about rape. For example: there is the view that rapists are unknown to their victims; that rapists are mentally ill; that a raped woman will be visibly upset after the event; that women fantasize rape; that women are malicious; and the apparently self-contradictory view that a woman cannot be raped against her will. Views such as these are used by police, consciously or unconsciously, to filter out reported cases of sexual assault that are deemed unworthy of further attention.
This is not a matter of conjecture on L'Heureux-Dubé's part: she cites academic studies that support the point. Studies also show that rape myths and stereotypes about women influence the thinking of judges and juries, which is one reason why conviction rates are low. For example, there was the infamous judge in Cambridge, Ontario who averred in a 1982 case that "[w]omen who say no do not always mean no" (341h). And an American study (with which Canadian data agree) found that "'Ij]urors are reluctant to convict the defendant when any testimony about prior sexual history is introduced in support of the consent defense'" (343d; italics removed).

But, according to L'Heureux-Dubé, the very idea that such evidence is relevant in a sexual-assault case is based on myth and stereotype. This being so, the evidence excluded by s. 276 is "simply irrelevant" (364c). Suppose, however, that it is false that no relevant evidence is excluded by the provision. Then there is a further point to be made, namely that the excluded evidence has an "extremely prejudicial effect on the trial of the legal issues" (364e), so that its exclusion is perfectly proper.

L'Heureux-Dubé summarizes her reasoning in remarks that may be reconstructed as the following conductive argument:

\begin{abstract}
Admittedly, s. 276 may prevent the accused in a sexual-assault trial from leading all relevant evidence. But the sexual-history evidence excluded by s. 276 "is either irrelevant or so prejudicial that its minimal probative value is overwhelmed by its distorting effect" (372c). Thus, s. 276, in excluding the sexual-history evidence that it does exclude, does not violate the principles of fundamental justice (where these include the principle that an accused person has the right to a fair trial).
\end{abstract}

\section{An Assessment:}

The issue that centrally divides the two judges is whether the prejudicial effect of the evidence excluded by s. 276 always outweighs its probative value. I believe that McLachlin succeeds in showing that it 
does not. What she does, in effect, is produce a convincing counter-example to the premise of L'Heureux-Dubé's summary argument - the claim that the sexual-history evidence excluded by s. 276 is "either irrelevant or so prejudicial that its minimal probative value is overwhelmed by its distorting effect." I have in mind her example of the father charged with sexual assault by his daughter (State v. Jalo). McLachlin is surely right that the evidence that s. 276 would have excluded in that case, namely that the daughter had had a sexual relationship with her brother, was, in the circumstances of the case, of "clear relevance" to the issue of whether her father sexually assaulted her; and surely its probative value would have substantially outweighed such prejudicial effect as it might have had.

But consider this objection. Someone presented with the facts of the Jalo case who believes the evidence relevant will do so because he or she believes that the father's explanation of why his daughter charged him with sexual assault is plausible if, as the father claims, the charge is false. His explanation is that his daughter reacted with animosity to his stopping her sexual relationship with her brother, and that it was out of animosity that she laid the charge. But the belief that this explanation is plausible if the charge is false presupposes a (false) sexist stereotype - a stereotype akin to one cited by L'Heureux-Dubé, namely that "the feminine character is especially filled with malice" (337a). Accordingly, someone presented with the Jalo facts who believes that the daughter's having had a sexual relationship with her brother is relevant to whether her father sexually assaulted her will do so on the basis of a belief that presupposes a (false) sexist stereotype.

Reply: To find that the father's explanation is plausible if the charge is false, one need only make the non-sexist, and plainly true, assumption that animosity is an intelligible reaction on the part of any person, male or female, whose will is thwarted by another, especially in a matter as significant for personal well-being as a sexual relationship. Thus the belief that the father's explanation is plausible if the charge is false does not presuppose a (false) sexist stereotype. Accordingly, to believe on the basis of that belief that the evidence in question in Jalo is relevant is not to believe it relevant on the basis of a belief presupposing such a stereotype. Hence the objection fails. I therefore continue to think that Jalo is a convincing counter-example to the premise of L'Heureux-Dubé's summary argument. (Here, and above, I assume that the sexual-history evidence in question would not have been admissible under one of the 'exception' clauses of s. 276. McLachlin obviously makes this assumption herself. Whether it is correct, I will not pause to consider.)

\section{Some Teaching Suggestions}

\section{Relevance:}

In A Practical Study of Argument (Wadsworth, 1992; hereafter cited as PSA), Trudy Govier mentions several reasons why "unwary audiences are often deceived" (152) by arguments with irrelevant premises. One possibility that she does not mention, but that it would be desirable for students to be brought to recognize, is that arguer and audience may consider the premises relevant (or fail to see that they are irrelevant) because, consciously or unconsciously, they subscribe to certain stereotypes or myths. This is apparent from the problem that led to the legislation reviewed in Canada's rape-shield decision.

From that problem it is a simple matter to construct an example that could be used with profit in an informal-logic class to make the point that, in a context of argumentation, highly consequential judgments of relevance may be accepted by arguer and audience on the basis of stereotype or myth. The example might go as follows: 
Smith is charged with raping Jones. At his trial, his lawyer cross-examines Jones on her sexual history and learns that she is 'unchaste'-she has engaged in nonmarital consensual sex, with a person other than Smith. This evidence is admitted by the judge as being relevant to the question whether Jones consented to the sexual activity that is at issue in the trial and to the question whether Jones is credible as a witness. From the evidence of Jones's sexual history the jury is therefore permitted to infer, and, in accordance with argumentation made by Smith's lawyer, does infer, that Jones is more likely to have consented to have sex with Smith on the occasion in question, and is less worthy of belief, than she would have been had she been "chaste'. ${ }^{2}$ Judge and jury accept, then, that the evidence of Jones's sexual history is positively relevant to

(1) Jones consented to have sex with Smith on the occasion in question, and to

(2) Jones is not credible as a witness.

The students would be told that while this example is hypothetical, it draws upon recent legal fact, namely that at common law in Canada prior to 1982 evidence that the complainant in a sexual-assault trial was 'unchaste' was considered relevant to the issues of consent and credibility in just the way that it is in the example. (On this point, see L'Heureux-Dubé, 345d-347b.) There might then be discussion of whether such evidence is relevant to those issues (or, more specifically, whether the evidence of Jones's 'unchasteness' is positively relevant to either (1) or (2)) discussion leading to the conclusion that the example is one in which a judge and jury accept a certain judgment of relevance because they subscribe, consciously or unconsciously, to an odious stereotype or myth, to the effect that women who have consensual sex outside marriage have, in the words of L'Heureux-Dubé, "a dual propensity: to consent to sexual relations at large and to lie" (346c).
The following question might then be raised: even if Jones's sexual history, as reported in the example, isn't positively relevant to (1) or (2), can realistic circumstances nevertheless be pictured in which evidence that the complainant in a sexualassault trial had had non-marital consensual sex with a person other than the accused would be relevant to the issue of whether she was raped by the accused? Following consideration of this question, the students would be presented with the facts of the Jalo case and asked to decide whether the fact that the daughter had had a sexual relationship with her brother is relevant, in the circumstances of the case, to whether, as the daughter charges, her father sexually assaulted her. They would be required to justify their answers to this question. Several of those (and there would surely be some) who offered justifications for the affirmative answer would then be questioned to determine whether they did so under the influence of a stereotype; if they did, they would be asked to consider whether the justifications presupposed a stereotype. Suppose it were agreed that they did not (as in my 'assessment' in Part 1). It would then be appropriate to make the following point: a category of evidence (e.g., sexualhistory evidence) and a type of factual question (e.g., did the accused commit the act that he or she is accused of having committed?) may be such that while in certain instances, or even normally, the belief that the former is relevant to the latter will be based on stereotype or myth, there are nonetheless instances in which evidence belonging to that category is relevant to a question of that type independently of stereotype or myth. ${ }^{4}$

\section{Conduction:}

According to Grovier, a conductive argument is an argument with the following characteristics: (a) "the pattern of support is convergent"5 (PSA 355), except "in the limiting case where there is only one 
premise" (Problems in Argument Analysis and Evaluation (Foris, 1987), 70; hereafter cited as Problems); (b) the "premises are put forward as separately being positively relevant to the conclusion" (PSA 355); (c) none of the premises entails the conclusion, nor do they jointly entail it; thus a conductive argument is never a deductively valid argument (PSA 308, 357 n. 2; Problems 70); (d) "[c]ounterconsiderations may be acknowledged by the arguer", a counterconsideration being a claim that is "negatively relevant to the conclusion of an argument" (PSA 355). (A counterconsideration is not a premise; rather, it "could be regarded as a kind of antipremise" (PSA 310).) By 'conductive argument' (reasoning) I mean what Govier means. ${ }^{6}$

Govier remarks that conductive arguments appear in many contexts, and mentions several (PSA 313). One, which she does not mention, is that of legal reasoning. The rape-shield decision is a case in point. For, as I observed above, the remarks in which L'Heureux-Dubé summarizes her reasoning on whether s. 276 violates the principles of fundamental justice can be reconstructed as a conductive argument. And this is a natural reconstruction. Thus L'Heureux-Dubé claims that "the argument that an accused is prevented [under s. 276] from adducing all relevant evidence going to innocence has little weight in this inquiry and must give way to other considerations" (372d). On my reconstruction, that "argument" is (what Govier calls) a counterconsideration, which is allegedly outweighed by a premise stating "other considerations".

One of McLachlin's central arguments also admits of a conductive reconstruction. The argument reviews three justifications for s. 276 and in each case presents one or more reasons why the section nevertheless "overreaches" (395f). On the reconstruction I have in mind, these reasons are premises offered in support of the conclusion that the wide reach of the section is unjustified, while each of the justifications figures in the argument as a counterconsideration to that conclusion.

On the other hand, in both L'HeureuxDubé and McLachlin there is reasoning that is not conductive but that a student of Govier might be tempted so to construe. In L'Heureux-Dubé the reasoning concerns whether "the effects of the measure [s. 276] are so deleterious that they outweigh the importance of the objective" (379d). In McLachlin the reasoning concerns essentially the same issue, namely, "the balance between the importance of the objective and the injurious effect of the legislation" (403c-d). According to Govier, conductive reasoning frequently involves the weighing of pros and cons. Thus a student of Govier might be tempted by the talk of outweighing in L'Heureux-Dubé and the talk of balance in McLachlin to interpret each judge's reasoning on the 'objective $v$. effect' issue as a conductive argument in which the injurious effect of the legislation counts against (or, as the case may be, for) the judge's conclusion on the matter, while the importance of the objective counts the other way. But this would be a mistake. Rather, what each judge does in effect is argue for a conclusion asserting that one factor outweighs another-in the case of L'Heureux-Dube that the importance of the objective outweighs the injurious effect of the legislation, in the case of McLachlin the converse. (I say 'in effect' because in each case the reasoning is elliptical.) And this is different from conductive reasoning that involves the weighing of pros and cons; for reasoning of that sort is based on the judgment that one factor, or set of factors, outweighs another, which is to say that some such judgment underlies the inference to the reasoning's conclusionrather than being itself the conclusion.

Govier is of course right that conductive arguments frequently involve the weighing of pros and cons. ${ }^{7}$ But it is worth adding that arguments that involve the weighing of one factor, or set of factors, against another need not be conductive. 
Students might be brought to recognize this by being given the exercise of deciding whether either McLachlin or L'HeureuxDubé engages in conductive reasoning on the 'objective v. effect' issue. And this exercise might be supplemented by one requiring them to reconstruct, in the form of a conductive argument, the remarks in which L'Heureux-Dubé summarizes her reasoning on whether s. 276 violates the principles of fundamental justice, and/or the reasoning in which McLachlin proceeds from a review of the justifications for s. 276 to the conclusion that the section's wide reach is unjustified. ${ }^{8}$

\section{Some Theoretical Matters}

L'Heureux-Dubé is strongly of the view that the area of the law concerned with sexual assault "has been particularly prone to the utilization of stereotype in determinations of relevance" (356e). "[T]he concept of relevance has been imbued with stereotypical notions of female complainants and sexual assault. That this is so is plain from the common law which held that evidence of 'unchasteness' was relevant to both consent and credibility" (355g-356). The common law would thus have tolerated arguments in which evidence that a female complainant in a sexual-assault trial was 'unchaste' was offered in support of a proposition affirming that she was not credible as a witness or that she consented to have sex with the accused. An argument of this sort may be reconstructed as what I shall call an argument from 'unchasteness', or as an argument that contains an argument from 'unchasteness' as a subargument. In this section I develop two analyses of a hypothetical argument from 'unchasteness', and connect them to a recent theory of propositional relevance. The discussion in which I do this leads me to present Govier with a problem in response to which she might revise her account of a conductive argument in a way that I describe. Relative to the revised account, L'Heureux-Dubé's summary argument is no longer conductive, but the argument of McLachlin's reconstructed in note (8) still is, or so I argue.

\section{Relevance:}

L'Heureux-Dubé says that "[a]ny connection between the evidence [of 'unchasteness'] sought to be adduced [in a sexual-assault triall and the fact or matter of which [at common law] it was supposedly probative must be bridged by stereotype (that 'unchaste' women lie and 'unchaste' women consent indiscriminately), otherwise the propositions make no sense" (355h). This isn't right. There are two propositions, one of which is given as evidence for the other. And they "make sense" independently of their being bridged by stereotype. What L'HeureuxDubé should rather have said is that the view that one of the propositions (the evidence proposition) is relevant to (or evidence for) the other "makes no sense" unless the propositions are bridged by stereotype. (By 'relevant' I mean here and, unless otherwise indicated, below 'positively relevant'.) Thus if the propositions are

(4) Jill is an 'unchaste' woman, and

(5) Jill lies,

then the view that (4) is relevant to (5) "makes no sense" unless the two propositions are connected by a third proposition stating a stereotype, for example:

(3) All 'unchaste' women lie.

The connection is made in the following linked argument:

(A) (3) All 'unchaste' women lie.

(4) Jill is an 'unchaste' woman.

Therefore,

(5) Jill lies.

I call argument (A) an argument from 'unchasteness'. An argument from 'unchasteness' (I stipulate for the purposes of this 
discussion) is a syllogism (by which I mean a two-premise linked argument with a single conclusion) containing a general premise (which may be universal or particular) attributing a certain characteristic, $\mathrm{c}$, to all or most 'unchaste' women (which attribution is a stereotype), a singular premise alleging of a certain woman, who is the complainant in a sexual-assault trial, that she is 'unchaste', and a conclusion attributing to that woman characteristic c. Such an argument may be a subargument of an argument whose main conclusion is, for example, that the complainant in question is not credible as a witness. Thus argument (A) might be a subargument of an argument containing the premise that no one who lies is credible as a witness and the conclusion (deduced from this premise jointly with (5)) that Jill is not credible as a witness.

On one analysis of argument (A), (4) is an evidence premise and (3) is a warrant premise. I borrow the terms 'evidence premise' and 'warrant premise' from James Freeman, ${ }^{9}$ and understand them as follows. An evidence premise of an argument is a premise whose function is to afford evidence for the conclusion (or for a conclusion) of the argument. A warrant premise of an argument is a premise that, if and only if it is true, warrants the judgment that some other premise of the argument (an evidence premise) is relevant to the conclusion for which it is offered as evidence, by explaining why the premise is relevant to that conclusion. ${ }^{10}$ What I shall call a warrant analysis of an argument interprets the argument as containing at least one evidence premise and at least one warrant premise. Thus the envisaged analysis of argument (A), on which (4) is an evidence premise and (3) a warrant premise, is a warrant analysis of that argument.

Suppose that the analysis is correct. Then if (3) warrants the judgment that (4) is relevant to (5), then (4) is relevant to (5). For if (3) warrants the judgment that (4) is relevant to (5), it explains why (4) is relevant to (5), and if it explains why (4) is relevant to (5), then (4) is relevant to (5). ${ }^{11}$ Now (3) warrants the judgment that (4) is relevant to (5) if and only if (3) is true. Thus, on the envisaged warrant analysis of argument (A), if (3) is true, then (4) is relevant to (5).

Objection: Suppose that if (3) is false, (4) is not relevant to (5). Then it is not the case that (4) alone is relevant to (5)-even if (3) is true. But if the envisaged warrant analysis of argument $(\mathrm{A})$ is correct, then if (3) is true, (4) alone is relevant to (5)even if (4) is not relevant to (5) if (3) is false. Thus that analysis is not correct.

This objection is modelled in part on an argument made by George Bowles. In "Propositional Relevance" (Informal Logic XII.2, Spring 1990, 65-77; hereafter cited as PR), Bowles defends a definition of 'relevance' according to which one proposition, (p), is (positively or negatively) relevant to another proposition, $(\mathrm{q})$, if and only if (p) makes ( $q$ ) certain or probable or improbable or impossible. In the same article, he considers the following objection:

it is possible for one proposition to be relevant to another without making the second certain, probable, improbable, or impossible. For instance, let ' $p$ ' be 'Aspirin tends to cause stomach bleeding' and ' $q$ ' 'You shouldn't take aspirin unless you really need it'. In this case, ' $p$ ' is relevant to ' $q$ 'it is a reason for ' $q$ '-, although it does not make ' $q$ ' certain, probable, improbable, or impossible. (72)

\section{Bowles replies:}

' $p$ 's being a reason for, and relevant to, ' $q$ ' depends on the truth of a third proposition, " $r$ '-e.g., 'Stomach bleeding is bad' or 'You shouldn't take anything that tends to cause stomach bleeding unless you really need it'. For if ' $r$ ' were false - e.g., if stomach bleeding were neither good nor bad, so that there were no reason to avoid taking something that tends to cause it-, ' $p$ ' would not be a reason for, or relevant to, ' $q$ '. Hence, it is not ' $p$ ' alone but the conjunction of ' $p$ ' and ' $r$ ' that is a reason for, and relevant to, ' $q$ '. And that conjunction does make ' $q$ ' probable if not certain. (72-3) 
Bowles argues, in part, as follows:

(6) (p)'s being a reason for, and relevant to, (q) depends on the truth of (r) [i.e., on the fact that ( $r$ ) is true].

Hence,

(7) It isn't (p) alone but the conjunction of (p) and (r) that is a reason for, and relevant to, (q).

(7) is the conjunction of

(7a) (p) alone isn't a reason for, and relevant to, (q), and

(7b) the conjunction of ( $p$ ) and $(r)$ is a reason for, and relevant to, $(q)$.

(7a) is open to different interpretations. It may mean

(7a') (p) alone-i.e., (p)-isn't a reason for, and relevant to, (q).

Or it may mean something like

$\left(7 a^{\prime \prime}\right)(p)$ alone - i.e., independently of any third proposition-isn't a reason for, and relevant to, (q).

Now obviously ( $\left.7 a^{\prime}\right)$ doesn't follow from (6). For even if (6) is true, it may be that (p) is a reason for, and relevant to, (q) just in case (r) is true, and that (r) is true. In this event, (p) is a reason for, and relevant to, (q), and so $\left(7 a^{\prime}\right)$ is false. Since it is obvious that ( $\left.7 a^{\prime}\right)$ does not follow from (6), Bowles surely does not interpret (7a) as ( $\left.7 a^{\prime}\right)$. It is much more likely that he would interpret it as $\left(7 a^{\prime \prime}\right)$. For $\left(7 a^{\prime \prime}\right)$ does follow from (6). However, $\left(7 a^{\prime \prime}\right)$ is compatible with

(8) (p) alone-i.e., (p) -is a reason for, and relevant to, (q),

which claim is, of course, the negation of (7a'). And (8), in turn, is compatible with (7b). For if (p) is a reason for, and relevant to, (q), as (8) asserts, it may also be that the conjunction of ( $p$ ) and (r) is a reason for, and relevant to, (q), as (7b) asserts. Thus even if Bowles has established the truth of (7b), a matter I will not pursue, as well as the truth of (7a) interpreted as $\left(7 a^{\prime \prime}\right)$, he has not shown that (8) is false. That is to say, for all Bowles has shown, it may be that (p) is a reason for, and relevant to, (q)just as Govier thinks it is.

Now the stated objection asserts that if the envisaged warrant anlysis of argument (A) is correct, then, if (3) is true, (4) alone is relevant to (5). This is true if '(4) alone is relevant to (5)' simply means '(4) is relevant to (5)'. But it is not true if '(4) alone is relevant to (5)' means something like '(4), independently of any third proposition, is relevant to (5)'; for an adherent of the analysis is at liberty to say that whether (4) is relevant to (5) depends on whether a third proposition-e.g., (3)-is true. Thus the question to ask in assessing the objection is whether the inference from

(9) if (3) is false, then (4) is not relevant to (5), to

(10) (4) alone - i.e., (4) - is not relevant to (5)

is sound. And plainly it is not any more than the inference from (6) to $\left(7 a^{\prime}\right)$ is sound. For even if (9) is true, it may be that (4) is relevant to (5) just in case (3) is true, and that (3) is true. In this event, (4) is relevant to (5). Thus, even if (9) is true, it may be that, in the relevant sense, (4) alone is relevant to (5). Thus the objection does not show that the envisaged warrant analysis of argument (A) is incorrect.

On that analysis, to repeat, (4) is relevant to (5) if (3) is true. The analysis does not, however, entail that (4) is relevant to (5) only if (3) is true (but that (3) warrants the judgment that (4) is relevant to (5) only if (3) is true). Thus the analysis does not entail (though it is compatible with the claim) that (3) is a presupposition of the judgment that (4) is relevant to (5).

As to whether (4) is relevant to (5), the analysis does not affirm either that it is or that it is not. By contrast, my second analysis of argument (A), which I shall now proceed to develop, affirms that (4) is not (positively) relevant to (5).

Consider the following argument:

(B) (p) Aspirin tends to cause stomach bleeding. 


\section{Therefore,}

(q) You shouldn't take aspirin unless you really need it.

On Bowles's theory of propositional relevance, $(p)$ is not (positively) relevant to (q) if (p) does not make (q) certain or probable (see PR 67, 69). Let us assume that, by this criterion, (p) is not (positively) relevant to $(q)$, and that in argument $(B)(p)$ is an evidence premise. Then, relative to Bowles's theory of propositional relevance, there exists in argument (B) what I shall call a relevance gap.

A relevance gap is a gap between an evidence premise of an argument and the conclusion for which the premise is offered as evidence, and exists if and only if the premise is not (positively) relevant to that conclusion.

Note that I have not claimed that there is a relevance gap in argument (B). Rather, I have claimed, on certain assumptions, that there is a relevance gap in the argument relative to a certain theory of propositional relevance. ${ }^{12}$ Assuming that relative to that theory the gap exists, it is filled, relative to the same theory, if we add to the argument as a further premise proposition (r) - "You shouldn't take anything that tends to cause stomach bleeding unless you really need it"-provided that on that theory the conjunction of $(p)$ and $(r)$ is relevant to $(q)$. Adding ( $r$ ) as a further premise to arrgument $(B)$ gives us

(C) (r) You shouldn't take anything that tends to cause stomach bleeding unless you really need it.

(p) Aspirin tends to cause stomach bleeding.

Therefore,

(q) You shouldn't take aspirin unless you really need it.

On what I shall call a relevance-gap analysis of argument $(\mathrm{C})$, there is a relevance gap between ( $p$ ) and ( $q$ ), but the gap is filled by (r) because (according to the analysis) the conjunction of $(p)$ and $(r)$ is relevant to $(q)$.
My second analysis of argument (A) is a relevance-gap analysis. It asserts that there is a relevance gap in argument $(A)$ between (4) and (5) but that the gap is filled by (3) because (according to the analysis) the conjunction of (3) and (4) is relevant to (5).

We now have two analyses of argument (A). Corresponding to each is a different view attributing a certain logical function to the argument's general (stereotypestating) premise-and, by extension, to the general (stereotype-stating) premise of any argument from 'unchasteness'. To the warrant analysis of argument (A) corresponds the view that the logical function of the argument's general premise, (3), is to warrant the judgment that the argument's singular premise, (4), is relevant to the conclusion, (5). To the relevance-gap analysis of the argument corresponds the view that (3)'s logical function is to fill a relevance gap in the argument, between (4) and (5). The former view does not, of course, entail that (3) does warrant the judgment that (4) is relevant to (5), and the latter view does not entail that (3) fills the alleged relevance gap; for a claim attributing a certain function to a premise of an argument does not entail that the premise succeeds in fulfilling that function. ${ }^{13}$

And plainly (3) does not fuflfill the function that the former view - the warrant view-attributes to it. For it fulfills that function only if it is true; but, at least when interpreted to mean that all women who have non-marital consensual sex habitually lie, it is false.

For these same reasons Bowles would deny that (3) so interpreted (and it is this interpretation of (3) that I have in mind in this paragraph and the following) fulfills the function that the latter view-the relevance-gap view-attributes to it-even if he agreed, as he obviously would, that there is a relevance gap between (4) and (5). Or so his reply to Govier suggests. He holds the following position: in the 'aspirin' example, (r)'s being true is necessary for $(p)$ to 
be relevant to (q); but (p) alone isn't relevant to $(q)$; rather, the conjunction of $(p)$ and $(r)$ is relevant to $(q)$. But then his point must be that $(r)$ 's being true is necessary for the conjunction of (p) and (r) to be relevant to (q). Evidently, then, he would say that, in the 'chastity-and-credibility' example, the conjunction of (3) and (4) is not relevant to (5) unless (3) is true. But (3) is false. Thus Bowles would not agree that the conjunction of (3) and (4) is relevant to (5), and so he would deny that (3) fills the relevance gap he would grant exists in argument (A) between (4) and (5).

However it is false that, in the 'aspirin' example, ( $r$ )'s being true is necessary for the conjunction of $(p)$ and $(r)$ to be relevant to (q). This is false on Bowles's own theory of propositional relevance, which allows that one proposition may be relevant to another even if the first is false. The conjunction of $(p)$ and $(r)$ is indeed relevant to $(q)$, but this is independent of the fact that (r) is true. On Bowles's theory of propositional relevance, it is, rather, a consequence of the fact that $(q)$ is "probable if not certain" given the conjunction of (p) and ( $r)$. If, similarly, (5) is probable or certain given the conjunction of (3) and (4), then, on Bowles's theory of propositional relevance, the conjunction of (3) and (4) is relevant to (5), despite the falsity of (3). In fact, (5) is certain given the conjunction of (3) and (4). Thus, on Bowles's theory of propositional relevance, the conjunction of (3) and (4) is relevant to (5). Hence, relative to that theory, (3) does fulfill the function that the relevance-gap view attributes to it - assuming that, relative to that theory, there is a relevance gap between (4) and (5); and plainly there is, for (4) does not make (5) probable or certain by Bowles's criteria. ${ }^{14}$

A relevance-gap analysis of argument (A) affirms both that there is a relevance gap in the argument, between (4) and (5), and that the conjunction of (3) and (4) is relevant to (5). This analysis, it is now apparent, is compatible with Bowles's theory of propositional relevance. More generally, that theory is compatible with a relevancegap analysis of any argument from 'unchasteness' whose singular premise does not make its conclusion probable or certain by Bowles's criteria, but whose conclusion is by those criteria made probable or certain by the conjunction of its premises; for in any such argument there is a relevance gap, relative to Bowles's theory, and the gap is filled, relative to that theory, by the argument's general (stereotype-stating) premise. (More generally still, Bowles's theory is compatible with a relevance-gap analysis of any syllogism containing an evidence premise that does not make the conclusion probable or certain by his criteria, but whose conclusion is by those criteria made probable or certain by the conjunction of its premises.)

On the other hand, Bowles's theory of propositional relevance is incompatible with a warrant analysis of an argument from 'unchasteness' whose singular premise does not make its conclusion probable or certain by his criteria-for example, argument (A). For if the argument's singular premise does not make its conclusion probable or certain by his criteria, it does not make the conclusion probable or certain by his criteria even if the argument's general premise is true. Thus, even if the argument's general premise is true, the singular premise is not relevant to the conclusion, relative to Bowles's theory of propositional relevance. But a warrant analysis of the argument will entail that the singular premise is relevant to the conclusion if the general premise is true. (For it will entail that if the general premise is true, it explains (in the sense indicated in note (11)) why the singular premise is relevant to the conclusion.) Thus a warrant analysis of the argument will be incompatible with Bowles's theory of propositional relevance. (So will be a warrant analysis of any syllogism containing an evidence premise that does not make the conclusion probable or certain by Bowles's criteria.) 
If, then, Bowles's theory is correct, a warrant analysis of an argument from 'unchasteness' is incorrect if the argument's singular premise does not make its conclusion probable or certain by his criteria. But is Bowles's theory correct? I shall confine myself here to one observation, namely that, applied to the 'aspirin' example, the theory has a counterintuitive result, if, as Govier claims and Bowles does not dispute, (p) - "Aspirin tends to cause stomach bleeding"-does not make (q)-"You shouldn't take aspirin unless you really need it" - probable or certain (by Bowles's criteria, I assume). For then, relative to Bowles's theory of propositional relevance, $(p)$ is not (positively) relevant to $(q)$. But that $(p)$ is not (positively) relevant to (q) is counterintuitive. For it is intuitively very plausible both that $(p)$ is relevant to (q) if $(p)$ is a reason for $(q)$ and that $(p)$ is a reason for $(q)$-that I am given a reason not to take aspirin unless I really need it if I am informed that aspirin tends to cause stomach bleeding. Hence it is intuitively very plausible that $(p)$ is relevant to $(q) .^{15}$

\section{Conduction:}

Suppose that $(p)$ is indeed relevant to (q). Then there is a third proposition which is true and whose truth (p)'s being relevant to $(q)$ depends upon trivially - the proposition that (p) is relevant to (q). Furthermore, if $(p)$ is relevant to $(q)$ by a general criterion of propositional relevance, CPR, then there is a third proposition (i.e., a proposition in addition to (p) and (q)) which is true and whose truth (p)'s being relevant to (q) depends upon criterially-a proposition whose conjunction with CPR entails that (p) is relevant to (q). (For example, if CPR asserts that one proposition is relevant to another that it makes probable, the proposition is that (p) makes ( $q$ ) probable.) Now Bowles believes, recall, that $(p)$ 's being relevant to $(q)$ depends on the truth of a third proposition, (r)-e.g., "You shouldn't take anything that tends to cause stomach bleeding unless you really need it". But he would say that (p)'s being relevant to (q) depends upon the truth of $(r)$ non-trivially and non-criterially.

Govier, as we know, believes that (p) is relevant to (q). Suppose that she too would say (as she might) that (p)'s being relevant to (q) depends non-trivially and noncriterially upon the truth of (r). (Hereafter when I use the verb 'depend' I shall omit the qualifying adverbial phrase "non-trivially and non-criterially', but in each case it is to be understood.) Then she would say that if ( $p$ ) is, but ( $r$ ) is not, a stated premise of an argument for (q) (as in argument (B)), the (positive) relevance of premise (p) to conclusion (q) depends on the truth of a third proposition, (r), that is not a stated premise of the argument. But if she would say this, she would also say that if a stated premise of an argument is relevant to the conclusion (or to a conclusion) of the argument, its being relevant to that conclusion may depend on the truth of a further proposition that is not a stated premise of the argument. And I think it is clear that Govier would say this. Thus, in evaluating a certain conductive argument (about the American Revolution), she says: "the supporting [stated] premises are relevant to the conclusion provided we grant the assumption behind the argument: that a typical revolution involves moves, often violent, by the poorer classes to upset a social structure" (PSA 427). If that assumption is true, the premises are relevant to the conclusion; indeed, since the argument is conductive, they are then separately relevant to the conclusion. Thus Govier would surely allow that if a stated premise of an argument is relevant to the conclusion (or to a conclusion) of the argument, its being relevant to that conclusion may depend on the truth of a further proposition that is not a stated premise of the argument, ${ }^{16}$

But then it is possible to present Govier with a problem. Let $(x)$ be a convergent argument with stated premises (a) and (b), 
which are "put forward as separately being positively relevant to the conclusion", (c) (PSA 355). Neither (a) nor (b) entails (c), nor do (a) and (b) jointly entail (c). But Govier would say, I shall assume, that (a) and (b) are separately relevant to (c). She would also say, I shall further assume, that (a)'s being relevant to (c) depends on the truth of a fourth proposition, (d), and that (b)'s being relevant to (c) depends on the truth of a fifth proposition, (e). Question: would Govier say that (d) and (e) are unstated premises of argument (x)? She would certainly say that they are unstated assumptions of the argument. But in her view an unstated assumption of an argument is not necessarily an unstated premise of the argument (see Problems 92). By what I shall call Govier's missing-premise criterion, an unstated assumption of an argument is an unstated premise of the argument if its truth is "a necessary condition for properly inferring the conclusion from the stated premises" (ibid.). ${ }^{17}$ Now it is proper to infer the conclusion of argument (x) from the stated premises only if (d) or (e) is true, or only if (d) and (e) are true, if (a)'s being relevant to (c) depends on the truth of (d) and (b)'s being relevant to (c) depends on the truth of (e). I am assuming that Govier would say that this relevance condition is satisfied. Thus her missingpremise criterion would require her to say that at least one of propositions (d) and (e) is an unstated premise of argument $(x) .^{18}$

But besides stating the missingpremise criterion, Govier outlines what I shall call a missing-premise procedure for deciding whether an argument has an unstated premise (Problems 102). The first step is to classify "the stated argument as being of some particular type". The next step is to ask whether the stated argument is "inferentially sound as an example of that type". If it is not, but would be if any one of "a candidate set of supplementary premises were added", then a member of that set may properly be considered an unstated premise of the argument (unless the argument is "a fallacy or a non sequitur"). Suppose it is decided in accordance with Govier's missing-premise procedure that proposition ( $\mathrm{r}$ ), say, is an unstated premise of a particular argument of type T. Then adding ( $r$ ) to the argument as a further premise turns the argument into an inferentially sound argument of that same type. It does not turn the argument into an inferentially sound argument of a different type; if it did, then the decision that ( $r$ ) is an unstated premise of the argument would not accord with Govier's missing-premise procedure. This point is crucial for the argument of the following paragraph.

Govier would classify argument (x), on my description of it, as conductive. Now suppose that the conjunction of premise (a) and proposition (d) entails conclusion (c), and that so does the conjunction of premise (b) and proposition (e). (Call this the entailment assumption.) Then if either (d) or (e) is added to argument (x) as a further premise, the resulting argument will not be a conductive argument but an argument of a different type-a deductively valid argument. ${ }^{19}$ Thus it would be contrary to Govier's missing-premise procedure to decide that (d), or that (e), is an unstated premise of argument $(\mathrm{x})$. But by Govier's missing-premise criterion at least one of propositions (d) and (e) is an unstated premise of the argument, if, as I am assuming Govier would say, (a)'s being relevant to (c) depends on the truth of (d) and (b)'s being relevant to (c) depends on the truth of (e) - even if (c) is entailed by the conjunction of (a) and (d) and by the conjunction of (b) and (e). Thus we have a case in which Govier's missing-premise criterion conflicts with her missing-premise procedure.

The problem that the case presents Govier with relies on three stated assumptions. If any of the assumptions is abandoned, the problem is dissolved. The first assumption is that Govier would say that the stated premises of argument $(x)$ are separately relevant to the conclusion. 
There is no reason to abandon this assumption, for Govier admits the possibility of an argument whose stated premises are separately relevant to the conclusion (cf. PSA 311)-for example, a convergent argument that is cogent as stated. The second assumption is that Govier would say that (a)'s being relevant to (c) depends on the truth of (d) and that (b)'s being relevant to (c) depends on the truth of (e), where (a) and (b), but not (d) and (e), are stated premises of argument $(\mathrm{x})$. There is no reason to abandon this assumption either, for, as I have already argued, Govier would say that if a stated premise of an argument is relevant to the conclusion (or to a conclusion) of the argument, its being relevant to that conclusion may depend on the truth of a further proposition that is not a stated premise of the argument. The third assumption is the entailment assumption, which, on the face of it, is perfectly reasonable. Thus the stated assumptions of the problem survive scrutiny.

Govier might respond to the problem by revising her position on missing premises. Alternatively, she might respond by revising her account of a conductive argument-for example, by adding to it the condition that none of the stated premises of a conductive argument is such that it is relevant to the conclusion (or to a conclusion) of the argument only if a further proposition is true whose conjunction with the premtise entails that conclusion. ${ }^{20}$

Let us now return to L'Heureux-Dubé's summary argument. Relative to Govier's account of a conductive argument, L'Heureux-Dubé's summary argument, as reconstructed earlier, is conductive. Minus its stated counterconsideration, the reconstructed argument is this:

(11) The sexual-history evidence excluded by s. 276 "is either irrelevant or so prejudicial that its minimal probative value is overwhelmed by its distorting effect".

Thus,

(12) S. 276, in excluding the sexual-history evidence that it does exclude, does not violate the principles of fundamental justice (where these include the principle that an accused person has the right to a fair trial).

(11) is relevant to (12) only if it is true that

(13) The exclusion [from a trial] of evidence that is either irrelevant or so prejudicial that its minimal probative value is overwhelmed by its distorting effect does not violate the principles of fundamental justice.

The conjunction of (11) and (13) entails (12). Thus, if Govier's account of a conductive argument is revised by adding to it the condition stated above, then, relative to the revised account, L'Heureux-Dubé's summary argument, as reconstructed earlier, will no longer be conductive.

Finally, let us revisit the argument of McLachlin's reconstructed in note (8). Relative to Govier's account of a conductive argument, that argument is conductive. Minus its stated counterconsiderations, and minus the premise of its subargument, the reconstructed argument is this:

(14) S. 276 categorically excludes evidence without permitting the trial judge to engage in the exercise of determining whether the possible prejudicial effect of the evidence outweighs its value to the truth-finding process.

(15) S. 276 impairs the ability of the trier of fact to determine the truth of a report of sexual offence.

(16) S. 276 goes further than required to protect privacy.

Thus,

(17) The wide reach of s. 276 is unjustified.

Premises (14)-(16) each specify (what McLachlin considers) a negative consequence of the wide reach of s. 276. Each of those premises is relevant to the conclusion, (17), granted the truth of a proposition to the effect that

(18) A criminal statute is of unjustified wide reach if and only if the consequences of its wide reach are negative (harmful), at least on balance. 
The conjunction of (18) and any, or all, of premises (14)-(16) does not entail (17). Hence none of those premises is relevant to (17) only if a further proposition is true whose conjunction with it entails (17). Thus, if Govier's account of a conductive argument is revised by adding to it the condition stated above, then, relative to the revised account, the argument of McLachlin's reconstructed in note (8) will still be conductive. ${ }^{21}$

\section{Notes}

1 I have benefited from comments made on an earlier draft of this paper by an Informal Logic referee.

2 In saying that the jury is permitted to draw, and does draw, these inferences, I am adopting language quoted by L'Heureux-Dubé, at $346 \mathrm{e}$, and used by McLachlin, at $386 \mathrm{c}$. (I adopted similar language in the second paragraph of the 'Background' section of Part 1.) Compare sub-section I of s. 276 of the Canadian Criminal Code as amended by Parliament in 1992; the sub-section responds to the common-law problem that led to the enactment of the version of s. 276 struck down in the rape-shield decision, and reads in part as follows:

In proceedings in respect of an offence [pertaining to sexual assault] ..., evidence that the complainant has engaged in sexual activity, whether with the accused or with any other person, is not admissible to support an inference that, by reason of the sexual nature of that activity, the complainant

(a) is more likely to have consented to the sexual activity that forms the subjectmatter of the charge; or

(b) is less worthy of belief.

3 Suppose, for example, that one of the justifications is that the father's explanation of why the charge was brought is plausible if the charge is false. I might find the father's explanation plausible because I subscribe to the sexist stereotype that "the feminine character is especially filled with malice". But the explanation (and hence the justification) does not presuppose this or any other sexist stereotype, for no such stereotype need be true if it is true that the explanation is plausible if the charge is false.

It would also be worth considering whether the legal reasoning in my $\mathrm{Smith/Jones} \mathrm{example}$ employs the right theory of relevance. I am indebted for this point to an Informal Logic referee, who wrote: "The . . example employs Keynes' theory of relevance, which says (very roughly) that $x$ is relevant to $y$ if it changes the probability of $y, \ldots$ according to that theory; the fact that the seven of diamonds has been withdrawn from a pack of playing cards and not replaced is positively relevant to the propo sition that the next card drawn will be the ace of clubs, since the probability of that event is now higher than it would have been otherwise. Since in a trial it is desirable to find out whether it is (to a high degree) more likely than not that the defendant did what he was accused of doing-not merely whether it is more likely than it would have been otherwise--, perhaps the wrong theory of relevance was employed. Perhaps a theory should have been employed that admits something as positively relevant to a proposition only if it makes that proposition more likely to be true than false." Such a theory is, for example, that of George Bowles, cited below.

5 Convergent support, as Govier understands it, is "[a] kind of support where premises work together in a cumulative way to support the conclusion, but are not linked. The bearing of one premise on the conclusion would be unaffected if the other premises were removed; however, the argument is strengthened when the premises are considered together, since more evidence is then offered" (PSA 59).

6 Govier explains in Problems (Ch. 4) that the category of conductive argument was first defined by Carl Wellman, Challenge and $R e$ sponse: Justification in Ethics (Carbondale: Southern Illinois University Press, 1971). See also David Hitchcock, Critical Thinking: A Guide to Evaluating Information (Toronto: Methuen, 1983) 105-6, 130-37.

7 I assume here that 'cons' are counterconsiderations understood a la Govier-hence that a 'con' is not a premise but "a kind of antipremise" (PSA 310),

$\$$ Obviously the suggested exercises would have to be accompanied by background 
information. The 'objective $v$. effect' exercise would require background information that I have not yet supplied. L'Heureux-Dubé and McLachlin are engaged in what is known as a 'section 1 analysis' when they consider the 'objective v. effect' issue. The purpose of a s. I analysis is to determine whether legislation that violates a Charter right can be saved under $s$. 1 of the Charter. It can, according to the test used by the Canadian Supreme Court, if and only if certain conditions are satisfied, one of which is that the importance of the objective of the legislation outweigh the legislation's injurious effect, and by a substantial margin if the injury is serious. For L'Heureux-Dubé, a s. 1 analysis is optional, since she finds that $s$. 276 does not violate the Charter rights in question. She argues that even if it did, it could be saved under s. I.

Some references for the three exercises, all to 66 Canadian Criminal Cases (3d). L'Heureux-Dubé's reasoning on the 'objective $v$. effect' issue is at 379d-g; McLachlin's is at $403 \mathrm{~d}-\mathrm{g}$. L'Heureux-Dubé's summary runs from $372 \mathrm{~b}$, sentence two, to 372e. McLachlin's "wide reach" reasoning is at $395 \mathrm{~g}-396 \mathrm{~g}$, but the preceding paragraph (395d-f) should be included to provide context.

Here is a conductive reconstruction of McLachlin's "wide reach" reasoning. Counterconsiderations are identified by the letter ${ }^{\prime} \mathrm{C}$ ' followed by a numeral.

Cl. S. 276 prevents judge and jury from being diverted by irrelevant evidence of other sexual conduct of the complainant which will unfairly prejudice them against the complainant.

But,

2. S. 276 categorically excludes evidence without permitting the trial judge to engage in the exercise of determining whether the possible prejudicial effect of the evidence outweighs its value to the truth-finding process.

C3. S. 276 encourages the reporting of sexual offences.

But,

4. S. 276 impairs the ability of the trier of fact to determine the truth of a report of a sexual offence.

C5. S. 276 protects the complainant's privacy. But,

6. S. 276 fails to permit an assessment of the effect on the complainant of the evidence in relation to the cogency of the evidence.
So,

7. S. 276 goes further than required to protect privacy.

So,

8. The wide reach of s. 276 is unjustified.

Note: It is important to distinguish between a premise offered in support of the conclusion of a conductive argument and a claim to the effect that a counterconsideration mentioned in the argument does not show that the conclusion is false. In the passage containing the reasoning I have reconstructed, McLachlin endorses two claims of the latter kind, namely: (a) to accept that persuasive evidence for the defence can be categorically excluded on the ground that it may encourage reporting and convictions is to say either that we assume the defendant's guilt or that the defendant must be hampered in his defence so that genuine rapists can be put down, neither of which views conforms to our notions of fundamental justice; (b) the constitutional right to a fair trial must take precedence over easing the plight of the witness in case of conflict. McLachlin regards (a) as a reason for denying that C3 shows that the wide reach of s. 276 is justified, and (b) as a reason for denying that $\mathrm{C} 5$ does so. Neither claim is a premise offered by her in support of (8).

9 James Freeman, Thinking Logically: Basic Concepts for Reasoning, Prentice Hall, Englewood Cliffs, New Jersey, 1993, 98.

10 Compare Freeman: "a premise is a warrant or functions as a warrant just when it serves to explain why some other premise is relevant to the conclusion it is claimed to support" (op. cit., 97).

"I I here use 'explains' in a 'success' sense, such that if (p) explains why (q), then (p) is the (or a) correct explanation of why $(q)$. In this sense of 'explains', '( $p$ ) explains why (q)' entails ' $(q)$ '.

12 The relevance gap that exists in argument (B) relative to Bowles's theory of propositional relevance (still assuming that, by Bowles's criterion, (p) is not (positively) relevant to (q)) is, relative to that same theory, what Govier, following Robert Ennis, calls an inference gap (see Problems, pp. 94-96; Robert H. Ennis, "Identifying Implicit Assumptions", Synthese, S1: pp. 61-86). For, ex hypothesi, relative to that theory the inference from (p) to (q) is unsound, precisely because, ex hypothesi, relative to that theory ( $p$ ) is not (positively) 
relevant to $(q)$. Govier remarks that "[s]ome people see [inference] gaps where others don't, due to disagreements about the theory of argument" (Problems, pp. 95-96). Similarly, some people may see a relevance gap where others don't, because they subscribe to different theories of propositional relevance.

13 Compare the following remark: "The logical role of premise (4) in argument (A) is to afford evidence for the conclusion, (5). But (4) is irrelevant to (5), hence does not afford evidence for (5), hence does not succeed in fulfilling its logical role in the argument.'

14 That is, by his criteria for when one proposition makes another probable or certain. Bowles says: " $p$ " makes " $q$ " certain if and only if the probability of ' $q$ ' conditional on ' $p$ ' is 1 ", and " $p$ ' makes ' $q$ ' probable if and only if the probability of ' $q$ ' conditional on ' $p$ ' is less than I but greater than $1 / 2^{\prime \prime}$ (PR 67). If so, then 'p' need not be true to make ' $q$ ' certain or probable. I disagree, in the belief that a false proposition cannot make another proposition probably true or certainly true. If so, then ' $p$ ' may not make ' $q$ ' certain even if the probability of ' $q$ ' conditional on ' $p$ ' is 1 , and ' $p$ ' may not make ' $q$ ' probable even if the probability of ' $q$ ' conditional on ' $p$ ' is less than 1 but greater than $1 / 2$. The phrases " $p$ ' makes ' $q$ ' certain" and " $p$ ' makes ' $q$ " probable", in Bowles's above-quoted formulas, should be replaced, I believe, by the phrases " ' $p$ ', if true, makes ' $q$ ' certain' " and " $p$ ", if true, makes ' $q$ " probable"", respectively.

15 Bowles might reply that $I$ recognize (p) as a reason for $(q)$ only because I recognize the truth of a third proposition, (r), and that this means that what is actually a reason for $(q)$ is not (p) alone-i.e., (p)-but the conjunction of (p) and (r), Perhaps I do recognize (p) as a reason for $(q)$ only because I recognize the truth of (r). But, I claim, (p) is a reason for $(q)$ even if I don't recognize the truth of ( $r$ ) and so fail to recognize that it is.

16 In the example given, Govier does not say (though she may believe) that the relevance of the argument's premises to the conclusion depends on the truth of the stated assumption; what she implies is that its truth is sufficient for their relevance to the conclusion non-trivially and non-criterially sufficient, she would say.

17 At any rate, remarks Govier makes on pp. 92-93 of Problems suggest that this is her missing-premise criterion. But remarks she later makes (ibid., 93-94, 96-99) suggest that her missing-premise criterion might better be worded as follows: an unstated assumption of an argument that is not a principle or rule of inference, or a meta-linguistic assumption, on which the argument depends is an unstated premise of the argument if its truth is a necessary condition for properly inferring the conclusion from the stated premises. Govier would say that, by this criterion, an argument's associated conditional is not a missing (unstated) premise of the argument; for in her view an argument's associated conditional is a "principle" of inference (tacitly) assumed by the argument (ibid., 96)

18 Here (and below) I assume that neither (d) nor (e) is what Govier would consider a principle or rule of inference, or a meta-linguistic assumption, on which argument $(x)$ depends.

19 A conductive argument is cogent, Govier believes, only if its premises "considered togeth$\mathrm{er}$, in light of counterconsiderations provide adequate support for the conclusion" (PSA 314). The premises of a conductive argument, though "put forward as separately being positively relevant to the conclusion" (PSA 355 ), are offered jointly in its support (see also PSA 48). Thus their conjunction is offered in its support. If a further premise is added that entails the conclusion, then the conjunction of the argument's premises will entail the conclusion, and so the argument will be deductively valid, hence no longer conductive. Here is evidence that for Govier a conductive argument is never a deductively valid argument: "one might . . have an argument with several distinct premises, each of which quite separately deductively entailed the conclusion. In such a case, the argument would be deductively valid and hence [my emphasis] would not be a conductive argument, though it would exemplify convergent support" (PSA 357 n. 2; see also PSA 308-9.) In Problems, Govier writes: "We cannot define conductive arguments solely with reference to the convergent support pattern, because if we were to do so, some deductive arguments would be conductive. . . In a conductive argument no one premise deductively entails the conclusion, nor do the premises entail the conclusion when considered together" $(70)$.

20 Call this condition $\mathrm{Cl}$. Here is an alternative, C2: it is not the case that the conclusion of a 
conductive argument may be properly inferred from the stated premises only if a further proposition is true that in conjunction with the stated premises entails the conclusion. $\mathrm{Cl}$ and $\mathrm{C} 2$ are not extensionally equivalent. Thus let $(y)$ be a convergent argument with stated premises $(\mathrm{l}),(\mathrm{m}),(\mathrm{n})$, and conclusion (o). Premises (I), $(\mathrm{m})$, and $(\mathrm{n})$ are put forward as separately being positively relevant to $(0)$. None of premises (1), (m), and (n) entails (o), nor do they jointly entail (o). But assume that $(n)$ is relevant to (o) only if a further proposition, $(w)$, is true, and that the conjunction of $(n)$ and $(w)$ entails (o). Then, by $\mathrm{Cl},(\mathrm{y})$ is not a conductive argument. But assume further that (1) and (m) are strong reasons for $(0)$ and that neither (1) nor $(m)$ is outweighed by any counterconsiderations to $(0)$. Then ( 0 ) may be properly inferred from the conjunction of $(1)$ and $(m)$ (or so Govier would say). Finally, assume that neither (1) nor $(\mathrm{m})$ is relevant to $(\mathrm{o})$ only if a further proposition is true whose conjunction with it entails (o). Then argument $(y)$ is conductive even relative to the account of a conductive argument that results from adding C2 to Govier's account. Thus the addition of $\mathrm{C} 2$ to that account does not prevent argument (y) from being conductive (relative to the revised account), but the addition of $\mathrm{Cl}$ does. Thus $\mathrm{C} 1$ and $\mathrm{C} 2$ are not extensionally equivalent.

21 In judging that (11) is relevant to (12) only if (13) is true, and that each of $(14)-(16)$ is relevant $10(17)$ if (18) is true, I rely on intuition. I do not have in mind a particular theory of propositional relevance - any more than Bowles has when, in reply to Govier's 'aspirin' objection, he says that (p)'s being a reason for, and relevant to, $(q)$ depends on the truth of a third proposition, ( $r$ ), on the ground that "if ' $r$ ' were false ... ' $p$ ' would not be a reason for, or relevant to, " $q$ " (PR 72-73). Bowles cannot be relying upon his own theory of propositional relevance when he says this, for if he were he would be begging the question (of the adequacy of his theory) against Govier; rather, he must take it to be intuitively clear that if ( $r$ ) were false, ( $p$ ) would not be a reason for, or relevant to, (q).

DEREK ALLEN

DEPARTMENT OF PHILOSOPHY

UNIVERSITY OF TORONTO

TORONTO, ONTARIO MSS IAI 